\title{
The Burden of Disease and the Changing Task of Medicine
}

\section{Citation}

Jones, David S., Scott H. Podolsky, and Jeremy A. Greene. 2012. "The Burden of Disease and the Changing Task of Medicine." New England Journal of Medicine 366 (25) (June 21): 2333-2338. doi:10.1056/nejmp1113569. http://dx.doi.org/10.1056/NEJMp1113569.

\section{Published Version}

doi:10.1056/nejmp1113569

\section{Permanent link}

http://nrs.harvard.edu/urn-3:HUL.InstRepos:11880309

\section{Terms of Use}

This article was downloaded from Harvard University's DASH repository, and is made available under the terms and conditions applicable to Open Access Policy Articles, as set forth at http:// nrs.harvard.edu/urn-3:HUL.InstRepos:dash.current.terms-of-use\#OAP

\section{Share Your Story}

The Harvard community has made this article openly available.

Please share how this access benefits you. Submit a story.

\section{Accessibility}


200th Anniversary Article

The Burden of Disease and the Changing Task of Medicine

David S. Jones, M.D., Ph.D., Scott H. Podolsky, M.D., and Jeremy A. Greene, M.D., Ph.D.

At first glance, the inaugural 1812 issue of the New England Journal of Medicine and Surgery seems reassuringly familiar: a review of angina pectoris, articles on infant diarrhea and burns. The apparent similarity to today's Journal, however, obscures a fundamental discontinuity. Disease has changed since 1812. People have different diseases, doctors hold different ideas about those diseases, and diseases carry different meanings in society. To understand the material and conceptual transformations of disease over the past 200 years, one must explore the inextricably social nature of disease.

Disease is always generated, experienced, defined, and ameliorated within a social world. Patients need notions of disease that explicate their suffering. Doctors need theories of etiology and pathophysiology that account for the burden of disease and inform therapeutic practice. Policymakers need realistic understandings of determinants of disease and medicine's impact in order to design systems that foster health. The history of disease offers crucial insights into the intersections of these interests and the ways they can inform medical practice and health policy.

\section{Epidemiologic transitions}


In addition to angina, diarrhea, and burns, early Journal issues examined gunshot wounds, spina bifida, Tetralogy of Fallot, diabetes, hernia, epilepsy, osteomyelitis, syphilis, cancer, croup, asthma, rabies, and urethral stones. Although some case reports describe patients who might walk into urgent care today, others are nearly unrecognizable. Apoplexy, a syndrome of fainting spells that might mean stroke, seizure, or syncope today, was understood to arise from a "nervous sympathy" by which the stomach influenced the head (1812d). Doctors agreed that even a near miss by a cannonball -- without contact -- could shatter bones, blind people, or even kill them (1812f). Reports of spontaneous combustion, especially of "brandy-drinking men and women," received serious, if skeptical, consideration (1812g). And physicians were obsessed with fevers - puerperal, petechial, catarrhal, even an outbreak of "spotted fever" in which some patients were neither spotted nor febrile (1812e). The bill of mortality from 1811 (see extract) contains both the familiar and the exotic (1812h). Consumption, diarrhea, and pneumonia dominated the mortality data, but teething, worms, and drinking cold water apparently killed as well.

A century later, the infections that filled the Journal had been redefined according to specific microbial causes. The Journal ran reviews of tuberculosis (1912b), gonorrhea (1912e), and syphilis (1912i). Diphtheria, measles, pneumonia, scarlet fever, and typhoid made frequent cameos, and Massachusetts still maintained a leper colony on Penikese Island (1912d). Tropical infections also fascinated authors, whether worms in immigrants or outbreaks of plague, yellow fever, and malaria in the nation's new tropical empire. 
Doctors in 1912 did have some reasons to celebrate. By any account, the previous year had been "the healthiest of which there is any record" (1912a). Nearly every Journal issue that year mentioned another centenarian, and coverage of the "overwhelming success" of U.S. athletes at the Stockholm Olympics celebrated American racial vigor (1912f). One editorial, describing progress made since the Journal's early years, rhapsodized about what another century of medical discovery might bring: "Perhaps in 1993, when all the preventable diseases have been eradicated, when the nature and cure of cancer have been discovered, and when eugenics has superseded evolution in the elimination of the unfit, our successors will look back at these pages with an even greater measure of superiority" (1912c).

Such paeans to progress, however, were accompanied by fear of the morbid consequences of modernization. One article described a new problem, "automobile knee," and decried the prevalence of "persons of extremely indolent habits of life" who no longer walked more "than the few steps that are needed from the chamber to the elevator, from the elevator to the dining-room, or lounging-room, and then to the automobile"(1912j). Long-standing concern about epilepsy, alcoholism, and feeblemindedness took on new relevance in a society increasingly preoccupied by fears of race suicide and the promise of eugenics (1912g, 1912h). Doctors struggled with cancers, eclampsia, impotence, heart disease (chiefly infectious or valvular, rather than atherosclerotic), and arthritis.

During the 20th century, heart disease, cancer, and other chronic conditions assumed more dominant roles (see graph), though outbreaks of infectious disease, from eastern equine encephalitis (1938) and kuru (1957) to legionnaires' disease (1977), AIDS 
(1981), and multidrug-resistant tuberculosis (1993), necessitated ongoing vigilance against microbes. New concerns also came to medical attention, from the terrifying consequences of thermonuclear war (1962) to the indolent but devastating effects of environmental pollution (1966) and climate change (1989). Optimism about prospects for future health persisted but remained tempered by concern about the pathologies of civilization. An obesity epidemic, feared in 1912, has come to pass. Our previously steady increase in life expectancy has stalled and may even reverse (2005).

\section{Definitions and consequences}

The material and conceptual dynamism of disease poses challenges: how do we define disease meaningfully, and how do we measure our burden of disease and set health policy priorities? These are deceptively simple questions. Merriam-Webster's Medical Dictionary's definition of disease as "an impairment of the normal state of the living animal or plant body" begs the question: What is normal? What is impaired? We cannot answer by reference to biology alone: the line between normal and pathological requires value judgments. As physicians know, not every symptom constitutes a disease. Nor, as anthropologists have shown, is it feasible simply to contrast "disease," as diagnosed by doctors, with "illness," as experienced by patients." As contemporary disputes over alcoholism, chronic fatigue syndrome, and attention-deficit disorder make clear, physicians are never the sole arbiters of disease.

Any responsible attempt to define disease must account for the phenomenon's complexity. A disease has characteristic signs and symptoms, afflicts particular groups of people, and follows a characteristic course. Doctors name a disease and work to 
identify its cause and develop ways to prevent and treat it. But patients also ascribe meaning to their suffering and assign responsibility for what went wrong. ${ }^{1}$ And diseases have utility, with concrete consequences for patients, doctors, and their institutions. ${ }^{2}$ They mediate patients' claims to the sick role and adjudicate access to health care resources. Disease definitions structure the practice of health care, its reimbursement systems, and our debates about health priorities and policies. These political and economic stakes explain the fierce debates that erupt over definitions of such conditions as chronic fatigue syndrome and Gulf War syndrome. Disease is a deeply social process. Its distribution lays bear society's structures of wealth and power. The responses it elicits illuminate strongly held values. ${ }^{3}$

The complexities and consequences of disease extend to its measurement. Even after a disease has been clearly defined, measuring its frequency, intensity, and relevance is not simple. Since the 17th century, polities have compiled causes of death into annual bills of mortality. Successive generations of demographers and epidemiologists have transformed such statistics into age-adjusted measures of disease-specific mortality and developed measures of morbidity and disease's impact on people's ability to lead meaningful, productive lives (including disability- and quality-adjusted life-years). But such measures reduce the complex experience of disease to a single coefficient.

A population's disease status can also be gauged by lists of common diagnoses at clinics or hospitals, but no single measure definitively characterizes a population's burden of disease. Choosing among metrics is as much about values and priorities as about science, and it directly affects health policy. Whereas advocates of clinical and research funding for cardiovascular disease might use mortality data to support their 
claims, mental health advocates can cite morbidity measures in seeking greater resources. Data on causes of childhood mortality would justify certain priorities; analyses of health care spending would justify others. An ideal, sophisticated health policy would integrate all measures to form a holistic map of the burden of disease, but in practice competing interests use different representations of disease burden to recommend particular policies.

\section{Accounting for the burden of disease}

Regardless of the metric chosen, any map of the burden of disease exposes disparities within and among populations. Two aspects of the burden of disease have remained particularly vexing: changes over time in the prevailing diseases and the persistence of health inequalities.

By examining the many new diseases that have appeared over the past two centuries, historians have categorized the ways in which diseases emerge. New causes (e.g., severe acute respiratory syndrome, motor vehicle accidents, radiation poisoning), new behaviors (cigarette smoking, intravenous drug use), and even the consequences of new therapies (insulin transforming the course and manifestations of diabetes) can produce new diseases. Changing environmental and social conditions can increase the prevalence of once-obscure ailments (myocardial infarction, lung cancer, kuru and "mad cow" disease). New diagnostic technologies and therapeutic capacity can unmask previously unrecognized conditions (hypertension). New diagnostic criteria can expand a disease's boundaries (enzyme leak myocardial infarction, major depression). Changing social mores can redefine what is or is not a disease (homosexuality, alcoholism, masturbation). New diseases can emerge as the result of conscious advocacy by 
interested parties (chronic fatigue syndrome, sick building syndrome). HIV-AIDS alone demonstrates many of these modes of emergence. The emergence, recognition, and impact of disease are never just a bio-scientific process; the advent of a new disease always involves social, economic, and political processes that shape its epidemiology and influence our understanding and response.

The interaction between the biologic and the social is equally apparent in diseases' decline. Cannonball injuries, a frequent cause of concern in 1812, disappeared from the Journal, only to be replaced by a new and more terrible litany of war-related injuries. Neurasthenia, a widespread phenomenon of depleted nervous energy in the late 19th century, has disappeared, but traces of it remained recognizable in other diagnoses throughout the past century. In some cases, a disease's decline clearly resulted from medical action. Immunizations eradicated smallpox and may someday eradicate polio. Genetic screening has led to dramatic reductions in Tay-Sachs disease, thalassemia, and familial dysautonomia (2009). But often the potential for eradication has been incompletely realized — witness the continued prevalence of AIDS and tuberculosis in low-income countries and of atherosclerotic heart disease globally.

Even as prevailing diseases have changed, health disparities have endured. Inequalities in health status have always existed, regardless of how health has been measured or populations defined. When Europeans arrived in the Americas, they witnessed stark disparities in the fates of European, American, and African populations. Experiencing the ravages of 19th-century industrialization, physicians grew familiar with health disparities between rich and poor. Health inequalities remain ubiquitous, not just 
among races and ethnic groups, but also according to geography, sex, educational level, occupation, income, and other gradients of wealth and power. ${ }^{4}$

The persistence of health inequalities challenges our scientific knowledge and political will. Can we explain them and alleviate them? Genetic variations don't explain why mortality rates double as you cross Boston Harbor from Back Bay to Charlestown or walk up Fifth Avenue from midtown Manhattan into Harlem. Nor do they explain why Asian-American women in Bergen County, New Jersey, live 50\% longer than Native American men in South Dakota. ${ }^{5}$ Although we know something about the relationships among poverty, stress, allostatic load, and the hypothalamic-pituitary-adrenal axis, doctors and epidemiologists need more precise models that fill in the steps between social exposure, disease, and death.

Accounting for the history of disease also requires us to examine why some disparities in disease are seen as proof of a natural order while others are considered evidence of injustice. The 4.3-year life-expectancy gap between blacks and whites in the U.S. provokes outrage, but the 4.9-year gap between men and women does not. It's tempting to assume that differences between the sexes are natural and those between races aren't. But a 19th-century Journal reader might be skeptical of this explanation: men then lived at least as long as women. The survival advantage of women that appeared in the 20th century owed as much to changes in childbearing, improvements in obstetrical practice, and a new epidemic of heart disease disproportionally affecting men as to differences between $\mathrm{X}$ and $\mathrm{Y}$ chromosomes. Health and disease disparities are contingent outcomes of the ways society structures the lives and risks of individuals. 
Recognition of the contingency of health inequalities should make them a target for intervention, yet the opposite has frequently happened: the ill health of impoverished or marginalized groups has been used against them — as evidence of their inferiority or as an argument that they're unworthy of assistance. Such sentiments drove tragic government policies toward African-Americans and Native Americans in the late 19th and early 20th centuries. They may underlie current policies that would limit health care access for mentally ill, impoverished, or immigrant populations.

\section{The roles of medicine}

Medical practice and health policy rely on the assumption that the solution to the problem of disease is to be found in physicians and their therapies. Physicians tend to credit biomedical science with 20th-century improvements in health and longevity. The history, however, is complex and contested.

For example, after Robert Koch's 1882 discovery of Mycobacterium tuberculosis and the advent of antibiotics in the 1940s, physicians claimed responsibility for the decline of tuberculosis in Europe and North America. But closer examination revealed that this decline had begun before Koch's discovery and had largely run its course before effective antibiotics became available. Medicine's critics instead credited improvements in the standard of living, especially diet. A similar debate has emerged about coronary artery disease. Heart disease, like tuberculosis, followed a century-long epidemic wave, peaking in the United States in the 1960s before beginning 50 years of decline. Researchers have struggled to determine how much credit to give to health care or riskfactor reduction (2007). The decline narrative and debates, however, have been 
complicated by countries, notably the Russian Federation and China, where coronary disease has recently increased, and by signs of a plateau and possible reversal of decline in the United States, Australia, and Western Europe (2005). The stakes of this debate are substantial, with implications for allocation of contested health care resources.

Is there a best health policy? Our goal should be an integrated policy under which health care and public health programs together fully eclipse the disease burden (see diagram). But the details depend on how we conceptualize and measure disease. And disease is never static. Just as organisms evolve to keep up with changing environmental conditions (the "Red Queen Effect"), medicine struggles to keep up with the changing burden of disease. Since therapeutic innovation takes time, the burden shifts even as solutions appear. By the time antibiotics and vaccines began combating infectious diseases, mortality had shifted toward heart disease, cancer, and stroke. Great progress has been made against these challenges, but the burden of disease will surely shift again. We already face increasing neuropsychiatric disease for which satisfying treatments don't yet exist.

In many respects, our medical systems are best suited for diseases of the past, not those of the present or future. We must continue to adapt health systems and health policy as the burden of disease evolves. But we must also do more. Diseases can never be reduced to molecular pathways, mere technical problems requiring treatments or cures. Disease is a complex domain of human experience, involving explanation, expectation, and meaning. Doctors must acknowledge this complexity and formulate theories, practices, and systems that fully address the breadth and subtlety of disease. 
From the Department of Global Health and Social Medicine, Harvard Medical School (D.S.J., S.H.P., J.A.G.); the Center for the History of Medicine, Countway Library of Medicine (S.H.P.); and the Division of Pharmacoepidemiology and Pharmacoeconomics, Brigham and Women's Hospital (J.A.G.) — all in Boston; and the Department of the History of Science, Harvard University, Cambridge, MA (D.S.J., J.A.G.).

Disclosure forms provided by the authors are available with the full text of this article at NEJM.org.

[box]

Historical Journal Articles Cited.

New England Journal of Medicine and Surgery and the Collateral Branches of Medical Science

1812a. Warren JC. Remarks on angina pectoris. 1:1-11.

1812b. Jackson J. Some remarks on the morbid effects of dentition. 1:12-25.

1812c. Bigelow J. Observations and experiments on the treatment of injuries occasioned by fire and heated substances. 1:52-64.

1812d. Warren JC. Cases of apoplexy with dissection. 1:34-41, 154-9.

1812e. Of the disease called the spotted fever. 1:228-44.

1812f. Wind of cannon balls. 1:309-10.

1812g. Spontaneous combustion in manufactories, \&c. 1:313-4. 
1812h. Abstract of the bill of mortality for the town of Boston. 1:320-1.

Boston Medical and Surgical Journal

1912a. 1911-A healthful year. 166:28.

1912b. Marshall HW. A few notes upon operative measures for tubercular knee affections. 166:35-43.

1912c. Past, present and future. 166:62-3.

1912d. Fire at the Penikese leper colony. 166:104.

1912e. Kaan GW. The relation of gonorrhea to pelvic disease. 166:556-60.

1912f. American supremacy at the Olympic Games. 167:102.

1912g. Mears JE. A further study of the problem of race betterment. 167:455-61.

1912h. Conservation and evolution. 167:518-9.

1912i. Knapp PC. Syphilis of the nervous system. 167:614-8.

1912j. The automobile knee. 167:816-7.

New England Journal of Medicine

1938. Fothergill LD, Dingle JH, Farber S, Connerley ML. Human encephalitis caused by the virus of the eastern variety of equine encephalitis. 219:411.

1957. Gajdusek DC, Zigas V. Degenerative disease of the central nervous system in New Guinea: The endemic occurrence of 'kuru' in the native population. 257:974-8.

1962. Ervin FR, Glazier JB, Aronow S, et al. Human and ecologic effects in Massachusetts of an assumed thermonuclear attack on the United States. 266:1127-37. 1966. Man and his environment. 275:788. 
1977. Fraser DW, Tsai TR, Orenstein W, et al. Legionnaires' disease. 297:1189-97.

1981. Durack DT. Opportunistic infections and Kaposi's sarcoma in homosexual men. 305:1465-7.

1989. Leaf A. Potential health effects of global climatic and environmental changes. $321: 1577-83$.

1993. Frieden TR, Sterling T, Pablos-Mendez A, Kulburn JO, Cauthen GM, Dooley SW. The emergence of drug-resistant tuberculosis. 328:521-6.

2005. Olshansky SJ, Passaro DJ, Hershow RC, et al. A potential decline in life expectancy in the United States in the 21st century. 352:1138-45.

2007. Ford ES, Ajani UA, Croft JB, et al. "Explaining the decrease in U.S. deaths from coronary disease, 1980-2000. 356:388-98.

2009. Lerner BH. When diseases disappear — the case of familial dysautonomia. $361: 1622-5$.

\section{References}

Kleinman A. Healers in the Context of Culture: An Exploration of the Borderland between Anthropology, Medicine, and Psychiatry. Berkleley: University of California Press; 1980.

1. Brandt AM. No magic bullet: A social history of venereal disease in the United States since 1880, with a new chapter on AIDS. New York: Oxford University Press, 1987.

2. Rosenberg CE. The tyranny of diagnosis: Specific entities and individual experience. Milbank Quarterly 2002;80:237-60. 
3. Rosenberg CE. Disease and social order in America: Perceptions and expectations. Milbank Quarterly 1986;64:34-55.

4. Marmot MG. The status syndrome: How social standing affects our health and longevity. New York: Times Books; 2004.

5. Murray CJ, Kulkarni SC, Michaud C, et al. Eight Americas: investigating mortality disparities across races, counties, and race-counties in the United States. PLoS Med 2006;3:e260.

[legends]

[extract]

Causes of Death in 1811. Abstract of the Bill of Mortality for the Town of Boston.

From 1812h.

[graph]

The Shifting Burden of Disease.

[diagram?]

Medicine, Public Health, and the Eclipse of Disease (Panel A), and the Red Queen Effect (Panel B). 
